\title{
Reliability comparison of a DC-DC converter placed in Building-Integrated Photovoltaic module frames
}

\author{
W. Van De Sande*, M. Daenen \\ IMO-IMOMEC \\ Hasselt University \\ Hasselt, Belgium \\ wieland.vandesande@uhasselt.be
}

\author{
K. Spiliotis, J. Gonçalves, S. Ravyts, \\ D. Saelens, J. Driesen \\ ESAT-ELECTA, BOKU-Building Physics \\ KU Leuven \\ Leuven, Belgium
}

\begin{abstract}
Building-Integrated Photovoltaics (BIPV) replace traditional building elements with power generating elements through the use of solar cells. One of the targets for this technology is to place the module-level power converter into the photovoltaic module's frame to achieve an integrated system. Temperature is the most influential parameter for a converter's reliability, its damage caused on the components needs to be studied in detail. In this paper, a reliability comparison based on a four-day mission profile has been made in order to assess the most reliable frame position for this converter to be placed in as all of them possess a different temperature profile. The results show that placing the converter in the lateral bottom of the frame is significantly more reliable than the mid or top position. In addition, a lifetime analysis is performed on the converter's dc-link capacitor in order to demonstrate the required methodology. In future work, this can be extended towards other sensitive components when appropriate lifetime models become available. These lifetime estimations can then be combined to achieve an overall BIPV system lifetime assessment.
\end{abstract}

Keywords-BIPV; integrated $D C / D C$ converter; reliability; mission profile; converter placement

\section{INTRODUCTION}

In the light of climate change and the European legislation for buildings, achieving energy-neutral buildings is one of the top priorities in the construction sector. Building-Integrated Photovoltaics (BIPV) present another option in order to reach this goal by replacing traditional building elements with power generating ones through the use of solar cells. The development of these BIPV modules focuses on various ways to make this technology more aesthetically and economically appealing. In this way, architects are able to facilitate their entry into new building projects. Another aim is to increase the flexibility of the modules by shaping and offering BIPV elements in different dimensions. However, this presents a diverse range of power profiles and thus a different power converter for each type is required. Integrating this module-level converter into the BIPV module's frame will therefore further increase its desirability on the market as a complete 'plug and play' product. Due to the frame's geometry, those different enclosures have a different temperature. A PV surface can heat up to $70^{\circ} \mathrm{C}$ or more which causes the temperature of adjacent enclosures to rise. Temperature is a significant operating parameter for electronic components as it affects not only their losses but also their reliability.
This paper presents a reliability study for the placement of a power converter inside a BIPV module's frame. Three different positions are considered; namely top, middle and lateral bottom, as shown in Fig. 2. The bottommost part of the frame is not being investigated due to the unknown rising heat from an underlying BIPV element in a building environment. The analysis is performed by calculating and comparing the damage on the converter's switch, namely the metal-oxide-semiconductor field-effect transistor (MOSFET), and the dc-link capacitor. The paper is constituted as follows: In section II, a four-day mission profile of simulated thermal frame data and measured electrical data is translated into the converter's housing box temperature by using an electro-thermal converter model. In section III, the temperature profiles of the switch and the capacitor are derived from their losses and the converter's housing box temperature. Next, the damage on the components during this four-day temperature profile is calculated and compared for the three frame positions. The methodology for sections II and III is summarized in the flowchart diagram displayed in Fig. 1. In section IV, a lifetime estimation of the dc-link capacitor is performed using a one-year temperature profile of the backside of the PV module.

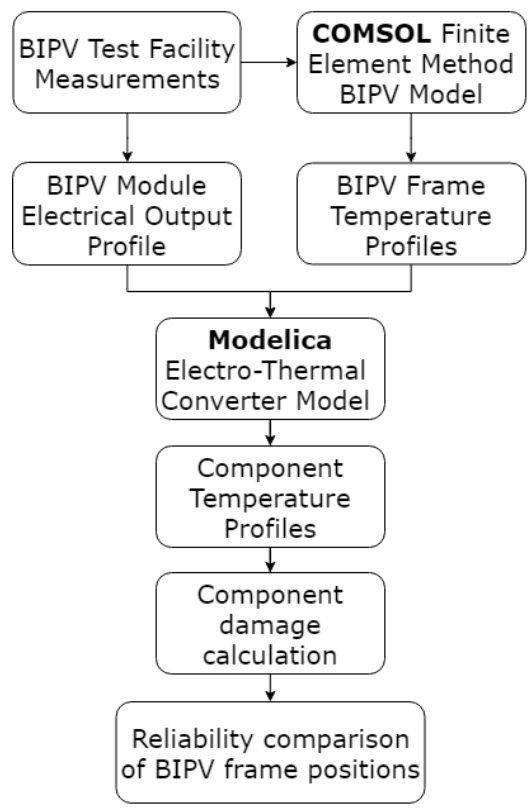

Fig. 1. Flowchart of the methodology in section II and III 


\section{INPUT PROFILES}

\section{A. Photovoltaic module output profile}

The PV module's electrical profile is measured in the BIPV test facility in Leuven, Belgium, and described in [1].It consists of a full-size floor-to-floor curtain wall element with a commercial-size 60-cells monocrystalline PV module built-in at the top part of the frame shown in Fig. 2. The bottom part comprises a triple-glazing Argon-filled window. Four subsequent hot and clear days are observed ranging from 26th to 29th August 2017 in order to observe a combination of both high power and ambient temperature in the BIPV module.

\section{B. Photovoltaic module frame temperature profile}

In order to evaluate the suitability of integrating the converter inside the BIPV frame, a Finite Element Method (FEM) model implemented in COMSOL has been used to study the temperature distribution over the entire BIPV element. As shown in Fig. 2, the top, mid and lateral bottom position of the BIPV frame are being investigated. The BIPV structure was modelled following the technical specifications of the prototype installed in the BIPV test facility in Leuven. On-site measured weather data was used as input to the simulations.

Solid layers were used to represent the air inside the cavity behind the PV module and inside the hollow aluminum frame. Equivalent conductivity coefficients were used for the air layers to account for the convection in vertical enclosures. The inside and outside environments were considered as a temperature node. The solar irradiance was applied to the PV and glass layers as a heat source. For the PV layer, the amount of energy converted into electricity was subtracted from the total solar irradiation assuming an average efficiency of 12\%. External heat transfer coefficients (HTC) were based on [2]. The heat transfer to the building interior was modelled assuming an internal temperature of $25^{\circ} \mathrm{C}$ and a HTC of $3 \mathrm{~W} / \mathrm{m}^{2} \mathrm{~K}$. Long-wave radiation losses to the ground and to the sky were taken into account separately. Finally, the surfaces around the frame were taken as adiabatic to represent the insulation around the frame perimeter.

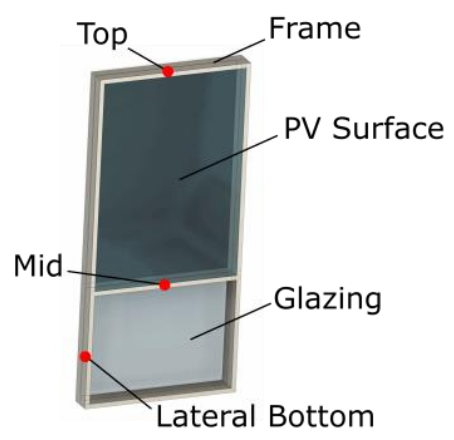

Fig. 2. Possible converter placement in the frame of the BIPV module

Due to high computational demand, a time step of $300 \mathrm{~s}$ was implemented for the simulations. Fast dynamic changes due to variations in wind speed and direction cannot be captured using such time step. However, despite the differences caused by the time step, the results presented in [2] indicate that the model is capable of predicting the maximum BIPV module temperature as well as the vertical temperature gradient.

\section{DC-DC converter housing box temperature profile}

The acquired electrical and thermal profiles from the previous subsections are translated into the converter's housing box temperature profiles, shown in Fig. 3, using an electrothermal model of a boost DC/DC converter. The model of the housing box with the converter has been implemented in Modelica and a typical topology from [3], which has been evaluated in [4], is assumed. The model estimates the losses per component as described in [5] using the electrical BIPV profile. Knowing the converter's surrounding temperature from the simulation in COMSOL and the losses generated in the converter's components, the temperature inside the converter housing box is derived with the use of a Cauer electro-thermal circuit model. An equivalent heat transfer coefficient has been used to represent radiative and convective heat exchange between the converter and its enclosure.

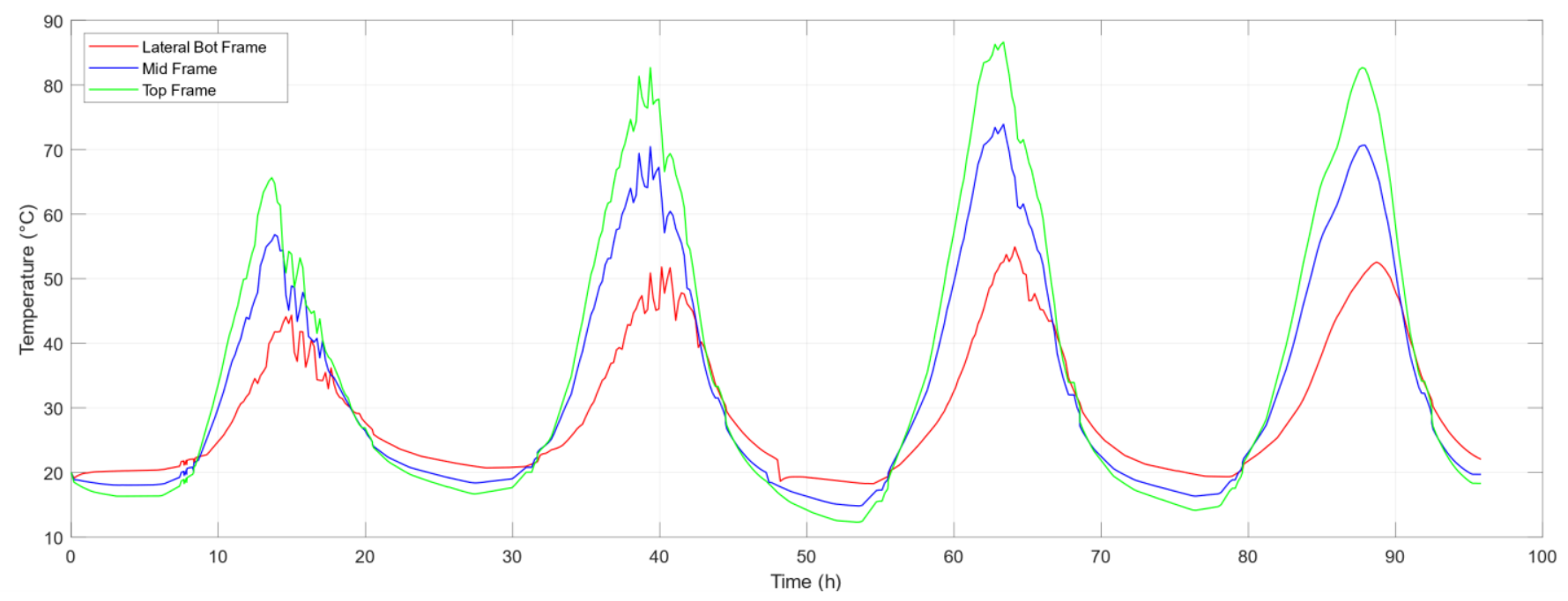

Fig. 3. Four-day simulated converter box temperature profiles for different converter positions 


\section{RELIABILITY COMPARISON}

In order to quantify the difference in converter reliability between the frame positions, a damage calculation on the weakest components is required. Traditionally, the electrolytic DC-link capacitor is considered to be the weakest component in the power converter due to its rapidly evaporating electrolyte. However, this type of capacitor can nowadays be replaced by several active or passive decoupling film capacitors [6] at the cost of a small increase in ripple current and voltage. The reliability focus has therefore shifted towards semiconductor switching devices such as the power MOSFET whose main failure mechanism is known to be bond wire lift-off and solder degradation [7]. This effect is caused by the mismatch in thermal expansion coefficients of aluminum (wires) or metal alloys (solders) and silicon (chips) [8]. In the following subsections, the damage on both the power MOSFET and the dc-link film capacitor is calculated and compared for the three frame positions.

\section{A. Power MOSFET damage model}

The aforementioned converter housing box temperature profile is translated to the junction temperature of the power MOSFET using its thermal resistance from junction to ambient $R_{t h}$, being $40 \mathrm{~K} / \mathrm{W}$, combined with the calculated losses. The thermal cycles in the junction temperature profile with their respective mean junction temperature $T_{j m}$, temperature range $\Delta T_{j}$ and cycle period $t_{o n}$ are counted using rainflow counting. This counting technique was invented by Endo in 1967 [9] and is considered to be the most widely used method for cycle counting. For a more detailed explanation of this technique and its applications please refer to [10]. The thermal cycles that occur on the power MOSFET's junction in the lateral bottom frame position are plotted in the resulting 3D histogram shown in Fig. 4. The $\mathrm{x}$-axis and the $\mathrm{y}$-axis of $\Delta T_{j}$ and $T_{j m}$, respectively, consist of $1{ }^{\circ} \mathrm{C}$ wide bins while the $\mathrm{z}$-axis visualizes the amount of times every combination of these two variables occurs in the temperature profile. The third important parameter for the damage calculation, namely the cycle period, $t_{o n}$ is not visualized but is taken into account for further calculations.

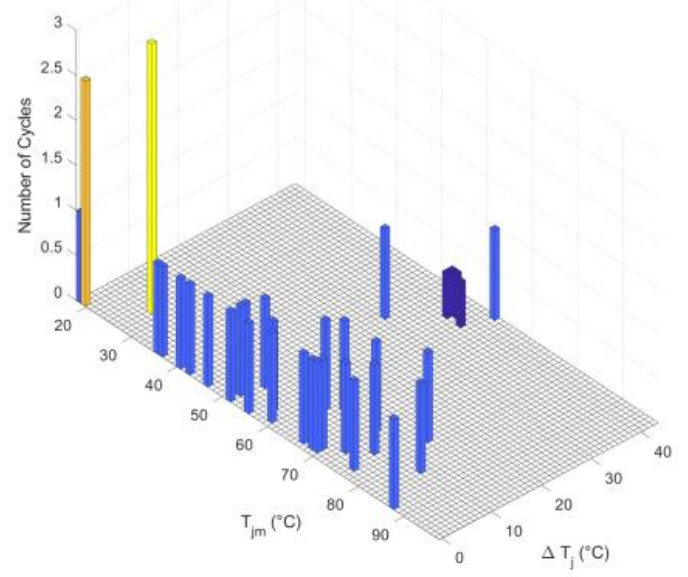

Fig. 4. Four-day thermal cycle rainflow counting histogram of the powe MOSFET junction temperature in the lateral bottom frame position
Due to the lack of power MOSFET lifetime models that incorporate the impact of the thermal cycles on the bond wires and solder joints, an insulated-gate bipolar transistor (IGBT) model from [11], shown in (1), is used. Although the structures of these components are different, the thermal mismatch that causes device failure occurs between the same materials. This translates into a common failure mechanism for both devices which makes the model acceptable for comparing the different frame temperature profiles while using the same device. The model calculates the amount of cycles $N_{f}$ for every separate thermal cycle with a specific $T_{j m}, \Delta T_{j}$ and $t_{o n}$ required for device failure through bond wire lift-off. The remaining parameters with their experimental validation conditions are summed up in Table I. Additional extrapolation is required due to several thermal cycles not being present within the validation boundaries. Some notable parameters include the bond wire aspect ratio ar and the activation energy $E_{a}$ that has been given an appropriate value for the previously mentioned failure mechanism.

$$
\begin{aligned}
N_{f}=A \times\left(\Delta T_{j}\right)^{\alpha} & \times(a r)^{\beta_{1} \Delta T_{j}+\beta_{0}} \times\left[\frac{C+\left(t_{o n}\right)^{\gamma}}{C+1}\right] \\
& \times \exp \left(\frac{E_{a}}{k_{b} \times T_{j m}}\right)
\end{aligned}
$$

TABLE I. IGBT LIFETIME MODEL PARAMETERS

\begin{tabular}{|c|c|c|}
\hline Parameter & Value & Experimental condition \\
\hline $\mathrm{A}$ & $3.4368 \times 10^{14}$ & \\
\hline$\alpha$ & -4.923 & $64 \mathrm{~K} \leq \Delta T_{j} \leq 113 \mathrm{~K}$ \\
\hline $\mathrm{ar}$ & 0.31 & \\
\hline$\beta_{1}$ & $-9.012 \times 10^{-3}$ & $0.19 \leq \mathrm{ar} \leq 0.42$ \\
\hline$\beta_{0}$ & 1.942 & \\
\hline $\mathrm{C}$ & 1.434 & $0.07 \mathrm{~s} \leq t_{\text {on }} \leq 63 \mathrm{~s}$ \\
\hline$\gamma$ & -1.208 & $32.5^{\circ} \mathrm{C} \leq T_{j} \leq 122^{\circ} \mathrm{C}$ \\
\hline $\mathrm{E}_{\mathrm{a}}$ & $0.06606 \mathrm{eV}$ & \\
\hline $\mathrm{k}_{\mathrm{b}}$ & $8.6173324 \times 10^{-5} \mathrm{eV} / \mathrm{K}$ & \\
\hline
\end{tabular}

\section{B. Film capacitor damage model}

Even though film capacitors are considered to be very reliable, especially compared with the aluminum electrolytic capacitors, they're still susceptible to temperature and voltage stress. The damage caused by these factors can be calculated using the lifetime model from [12], shown in (2).

$$
L=L_{0} \times\left(\frac{V}{V_{0}}\right)^{-n} \times 2^{\frac{T_{0}-T}{10}}
$$

This lifetime model is based around the two main degradation mechanisms in capacitors namely deterioration of the dielectric materials and an increasing leakage current. The model can be applied to both film and electrolytic capacitors by adjusting the voltage stress exponent $n$. The calculation is based on the Arrhenius acceleration factor which uses the rated lifetime $L_{0}$ under the rated temperature $T_{0}$ and rated voltage $V_{0}$ as an input. These values are provided by the manufacturer and are respectively 200000 hours at $85^{\circ} \mathrm{C}$ and $100 \mathrm{~V}$. The latter, however, will not be taken into account as this paper is a comparison of different temperature profiles and it is also assumed that there is no voltage derating in the dc-link 
capacitor. Hence, the lifetime can be calculated by discretizing the temperature profiles from Fig. 3 and calculating the actual lifetime for every separate temperature point.

\section{Damage comparison}

The final step for the comparison of the converter placement in the BIPV frame involves the accumulation of the damage caused by the various temperature profiles on its components. For the power MOSFET, the Palmgren-Miner linear damage hypothesis from [13], shown in (3), is used to calculate the total lifetime consumption $\mathrm{LC}_{\text {switch }}$. This rule incorporates the damage caused by every half or full thermal cycle $n$ with a specific $N_{f}$ calculated from (1).

$$
L C_{\text {switch }}(\%)=\sum_{i=1}^{k} \frac{n_{i}}{N_{f}} \times 100
$$

For the film capacitor, the accumulated lifetime consumption $\mathrm{LC}_{\text {cap }}$ for every discretized point is calculated using (4) with $\Delta t$ being the sample time of $300 \mathrm{~s}$ and $L$ the actual lifetime calculated from (2) for every sample point.

$$
L C_{\text {cap }}(\%)=\sum_{i=1}^{k} \frac{\Delta t}{L_{i}} \times 100
$$

The results of the accumulated damage from the various frame temperature profiles can be found in Table II. An LC of $100 \%$ corresponds with a device failure caused by the failure mechanism of the respective lifetime model. The lateral bottom position of the BIPV frame from Fig. 2 looks to be the most reliable position for the placement of a module-level power converter. The difference in damage on the components between the three positions can mainly be explained through the increased temperatures close to the BIPV module and the rising heat at the top. The lateral bottom position also has increased heat transfer towards the Argon window and the climatized work offices.
TABLE II. FOUR-DAY COMPONENT LIFETIME CONSUMPTION FOR 3 DIFFERENT FRAME POSITIONS

\begin{tabular}{|c|c|c|c|}
\cline { 2 - 4 } \multicolumn{1}{c|}{} & Top & Mid & Lateral bot \\
\hline $\mathrm{LC}_{\text {switch }}(\%)$ & $6.97 \times 10^{-3}$ & $4.09 \times 10^{-3}$ & $1.82 \times 10^{-3}$ \\
\hline $\mathrm{LC}_{\text {cap }}(\%)$ & $5.38 \times 10^{-3}$ & $2.89 \times 10^{-3}$ & $1.35 \times 10^{-3}$ \\
\hline
\end{tabular}

\section{DC-LINK CAPACITOR LIFETIME ESTIMATION}

A lifetime analysis on the dc-link film capacitor is performed in order to demonstrate the required methodology. In the future, this will be extended towards the other sensitive components of the converter when the appropriate lifetime models become available. These lifetime estimations can eventually be combined to achieve an overall BIPV system lifetime assessment. As in the previous section, a temperature profile is discretized and the actual lifetime per sample point is calculated and accumulated using (4). However, this is an ideal lifetime estimation which does not include variations from the manufacturing process or variations in the temperature due to local weather fluctuations. Therefore, a Monte-Carlo based reliability assessment, as used in [14], is performed in order to introduce uncertainty from these variations into the calculated lifetime. Lastly, the end of useful life is defined as B10 or the amount of hours for $10 \%$ of the capacitors to fail.

\section{A. Ideal lifetime estimation}

The one-year temperature profile shown in Fig. 5 is measured through a thermocouple on the backside of the BIPV element from [1] and is used as the input for this lifetime calculation. The measurements were taken from the period of June 2017 until June 2018 with a sample time of 1 second which was afterwards downscaled to 1 minute for computational reasons. This profile is comparable to the temperatures in the middle frame position from Fig. 3 and is considered a good approximation of the converter's housing box temperature.

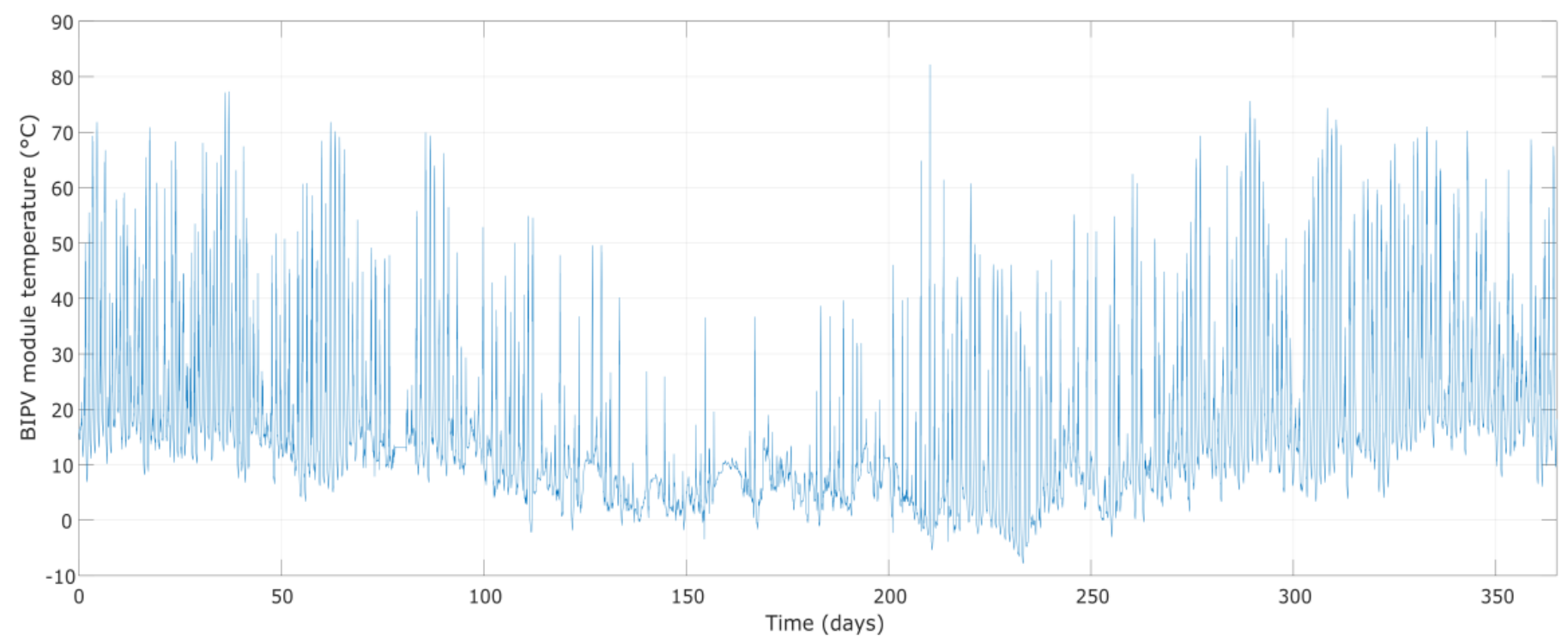

Fig. 5. One-year BIPV backside module temperature profile 
In practice, the converter will be installed in the lateral bottom part of the frame, as concluded in the previous section, leading to a slightly underestimated lifetime for the capacitor. The model from (2) is again used to quantify the effect of the temperature on the lifetime of the capacitor for every sample point. These values are then accumulated using (4) resulting in a one-year lifetime consumption of $8.32 \times 10^{-2} \%$ which translates into an ideal lifetime of 1202 years for the film capacitor. This large value can be explained due to an already high rated lifetime L0 of 200000 hours at a constant rated temperature of $85^{\circ} \mathrm{C}$.

\section{B. Monte carlo reliability assessment}

The previous subsection provides a lifetime estimation for the ideal case without including variations in both the capacitor's manufacturing process and thus its properties or the variations in the thermal stress caused by locally shifting weather conditions. In order to acquire a general idea about the actual useful lifetime for this worst case scenario, an uncertainty of $5 \%$ on the temperature profile must be taken into account. This uncertainty value is a rough estimation and can still be adjusted afterwards if it deems to be unrealistic. Because the input temperature is dynamic, it ought to be changed into an equivalent static variable in order to apply this uncertainty. The equivalent static temperature $T_{m}$ ' must inflict the same amount of lifetime consumption on the film capacitor during the oneyear measurement period as the dynamic variable. By solving the lifetime model from (2) towards the operating temperature $T$, using an actual lifetime $L$ of 1202 years and the aforementioned rated lifetime $L_{0}$ and rated temperature $T_{0}$, this results in a $T_{m}$, of $27.81{ }^{\circ} \mathrm{C}$. Lastly a normal distribution of 10000 samples is generated with an average value $\mu$ equal to $T_{m}$ ' and a standard deviation $\sigma$ equal to the uncertainty of $5 \%$. Every variation in the mean static temperature is translated into the respective film capacitor lifetime or time to failure according to (2) and plotted in Fig. 6. The probability density function PDF for this distribution, which is drawn in red, can be translated into the cumulative density function CDF by integration.

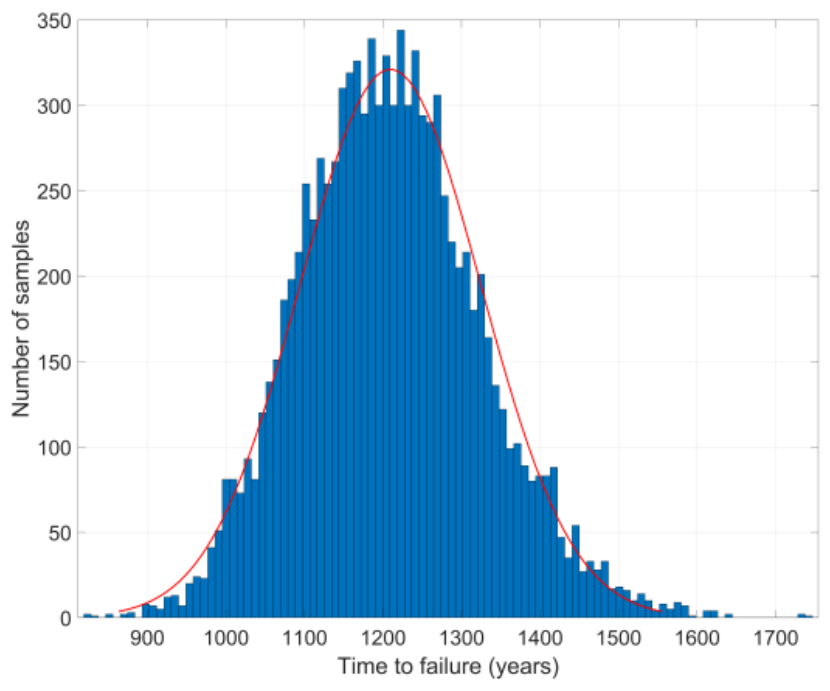

Fig. 6. Lifetime distribution for the dc-link film capacitors
The latter can be used to determine B10 or the time to failure for $10 \%$ of the devices to fail. For this distribution, this results in an end of life of 1063 year according to the lifetime model of [12]. Therefore, it seems unlikely that the film capacitor will be the first component to fail in the converter.

\section{CONCLUSION}

In this paper, the integration of a micro-converter into the BIPV frame has been considered. Different positions for the converter placement have been studied in terms of their impact on the converter's reliability. Experimental measurements alongside simulations using Modelica- and COMSOLdeveloped models have been used to produce the input for the damage estimation onto the converter's power MOSFET and dclink film capacitor. The damage comparison from section III shows that the lateral bottom position in the proposed frame design is significantly more reliable than the middle or top position. From the lifetime estimation of section IV it seems unlikely that the film capacitor will be the first component to fail due to its high predicted lifetime. In the future, this methodology will be extended towards the other sensitive components of the converter when the appropriate lifetime models become available. These lifetime estimations can eventually be combined to achieve an overall BIPV system lifetime assessment.

\section{ACKNOWLEDGMENT}

The results presented in this paper are part of a greater effort towards an integrated BIPV simulation framework supported by the European Union, the European Regional Development Fund ERDF, Flanders Innovation and Entrepreneurship and the Province of Limburg.

\section{REFERENCES}

[1] J. Lehmann, W. Parys, J. Gonçalves, G. Yordanov, K. Baert, en D. Saelens, "Experimental analysis of the performance of a BIPV curtain wall component", Advanced Building Skins Conference 2017.

[2] J. Gonçalves, J. Lehmann, G. H. Yordanov, W. Parys, K. Baert, en D. Saelens, "Experimental performance of a curtain wall BIPV element under realistic boundary conditions", EUPVSEC 2018

[3] N. Mohan, T. M. Undeland, en W. P. Robbins, Power Electronics: Converters, Applications, and Design, 3 edition. Hoboken, NJ: Wiley, 2002.

[4] S. Ravyts, M. Dalla Vecchia, J. Zwysen, G. Van den Broeck, en J. Driesen, "Study on a cascaded DC-DC converter for use in BuildingIntegrated Photovoltaics", in IEEE Texas Power and Energy Conference (TPEC), 2018.

[5] D. D. Graovac, M. Pürschel, en A. Kiep, "MOSFET Power Losses Calculation Using the Data- Sheet Parameters", p. 23, 2006.

[6] B. Karanayil, V. G. Agelidis, en J. Pou, "Evaluation of DC-link decoupling using electrolytic or polypropylene film capacitors in threephase grid-connected photovoltaic inverters", IECON Proc. Ind. Electron. Conf., nr. 1, pp. 6980-6986, 2013.

[7] R. Ruffilli e.a., "Aluminum metallization and wire bonding aging in power MOSFET modules Marcelot, M Legros To cite this version : ScienceDirect Aluminum metallization and wire bonding aging in power MOSFET modules", 2017.

[8] K. B. Pedersen en K. Pedersen, "Bond wire lift-off in IGBT modules due to thermomechanical induced stress", Proc. - 2012 3rd IEEE Int. Symp. Power Electron. Distrib. Gener. Syst. PEDG 2012, pp. 519-526, 2012.

[9] T. Endo, K. Mitsunaga, en H. Nakagawa, "Fatigue of metals subjected to varying stress prediction of fatigue lives", in Preliminary Proceedings 
of the Chugoku-Shikoku District Meeting, Japanese Society of Mechanical Engineers, Tokyo, 1967, pp. 41-44.

[10] P. Johannesson, Rainflow analysis of switching markov loads, nr. February. 1999.

[11] U. Scheuermann, R. Schmidt, P. Newman, S. E. Gmbh, en C. Kg, "Power cycling testing with different load pulse durations", Iet, pp. 1-6, 2014.

[12] A. Overview, H. Wang, H. Wang, en F. Blaabjerg, "Reliability of Capacitors for DC-Link Applications in Power Electronic Converters Reliability of Capacitors for DC-Link Applications in Power Electronic Converters - An Overview", nr. September, 2014.

[13] M. Miner, "Cumulative damage in fatigue", Trans. ASME, vol. Series E. J. Appl. Mech., nr. Vol. 12, pp. 159-164, 1945.

[14] A. Sangwongwanich, Y. Yang, D. Sera, en F. Blaabjerg, "Lifetime evaluation of $\mathrm{PV}$ inverters considering panel degradation rates and installation sites", Conf. Proc. - IEEE Appl. Power Electron. Conf. Expo. - APEC, pp. 2845-2852, 2017.

[15] A. Belkaid, I. Colak, en K. Kayisli, "A Comprehensive Study of different Photovoltaic Peak Power Tracking Methods", 6th Int. Conf. Renew. Energy Res. Appl. ICRERA 2017, vol. 5, 2017.

[16] V. A. K. Prabhala, M. Khazraei, en M. Ferdowsi, "A new control strategy for a class of multiple-input DC-DC converters", in 3rd International Conference on Renewable Energy Research and Applications, ICRERA 2014, 2014, pp. 508-513.

[17] K. Kajiwara, N. Matsui, en F. Kurokawa, "A New MPPT Control for Solar Panel under Bus Voltage Fluctuation”, in 6th International
Conference on Renewable Energy Research and Applications, ICRERA 2017, 2017, vol. 5, pp. 5-8.

[18] C. H. H. Basha, C. Rani, en S. Odofin, "A review on non-isolated inductor coupled dc-dc converter for photovoltaic grid-connected applications", Int. J. Renew. Energy Res., vol. 7, nr. 4, 2017.

[19] A. Alzahrani, P. Shamsi, en M. Ferdowsi, "An interleaved non-isolated DC-DC boost converter with diode-capacitor cells", in 6th International Conference on Renewable Energy Research and Applications, ICRERA 2017, 2017, vol. 2017-Janua, pp. 216-221.

[20] K. R. Bharath, H. Choutapalli, en P. Kanakasabapathy, "Control of bidirectional DC-DC converter in renewable based DC microgrid with improved voltage stability", Int. J. Renew. Energy Res., vol. 8, nr. 2, 2018.

[21] S. Reddy Addula en M. Prabhakar, "Coupled Inductor Based Soft Switched Interleaved DC-DC Converter for PV Applications”, Int. J. Renew. Energy Res., vol. 6, nr. 2, 2016.

[22] P. Nammalvar, S. Ramkumar, en R. Umadevi, "Cost Effective Solitary Stage Single Phase Inverter for Solar PV Integration in to Grid”, Int. J. Renew. Energy Res., vol. 8, nr. 3, 2018.

[23] S. Ganesan, V. Ramesh, en S. Umashankar, "Performance Improvement of Micro Grid Energy Management System using Interleaved Boost Converter and P\&O MPPT Technique", Int. J. Renew. Energy Res., vol. 6, nr. 2, pp. 663-671, 2016.

[24] F. Blaabjerg, Y. Yang, K. Ma, en X. Wang, "Power Electronics - The Key Technology for Renewable Energy System Integration Demands to Renewables", in 4th International Conference on Renewable Energy Research and Applications, ICRERA 2015, 2015, pp. 22-25. 